\title{
Sobre letrados chinos y bogas amazónicos: La participación indígena en la producción del conocimiento cartográfico y geográfico jesuita en Asia y América
}

\author{
Roberto Chauca Tapia ${ }^{1}$ \\ Recibido: 10 de abril de 2016 - Aceptado: 10 de mayo de 2016
}

\begin{abstract}
Resumen
En el campo de la producción cartográfica jesuita en América, la contribución indígena ha sido difícil de examinar y, en consecuencia, tradicionalmente obliterada. La situación de la producción científica jesuita en Asia es, sin embargo, completamente distinta, pues allí la discusión ha girado en torno al grado de influencia mutua ejercida tanto por la comunidad misionera europea como por la intelligentsia local. Una comparación entre ambas empresas misioneras, con particular énfasis en los jesuitas de China y del Amazonas español, nos ayudará a poner en mejor perspectiva hasta qué nivel las sociedades nativas, ya sean asiáticas o sudamericanas, proveyeron un tipo de conocimiento que fue considerado vital y necesario para la producción de conocimiento geográfico y cartográfico entre las comunidades jesuitas en dichas partes del mundo. De esta manera, el principal objetivo es recuperar la participación indígena para el caso de la producción cartográfica y geográfica jesuita del Amazonas colonial.
\end{abstract}

Palabras clave: cartografía, indígenas, jesuitas, Amazonía, China.

On Chinese literati and Amazonian aides: Indigenous participation in the production of cartographic and geographic Jesuit knowledge in Asia and America

\footnotetext{
Abstract

In the study of the Jesuit cartographic production in the Americas, the indigenous contribution has been difficult to examine and, as a result, traditionally obliterated. The situation of the production of Jesuit science in Asia is, howe-
}

Peruano. Doctor en Historia por la Universidad de Florida, Estados Unidos de América. Docente en el Instituto de Letras de la Universidad de Brasilia, Brasil. E-mail: rchaucat@hotmail.com 
ver, completely different because the discussion has dealt with the degree of mutual influence between the European missionary community and the local intelligentsia. A comparison between both missionary enterprises, with a particular emphasis on the Jesuits in China and in the Spanish Amazon, will help us better situate the extent to which native societies, either Chinese or Amazonian, provided a type of knowledge that was considered vital and necessary for the production of geographic and cartographic knowledge among Jesuit communities in those parts of the globe. Thus, the main objective is to underscore the indigenous participation in the case of the Jesuit cartographic and geographic production in early modern Amazonia.

Keywords: cartography, natives, Jesuits, Amazonia, China.

\title{
Sobre intelectuais chineses e auxiliares amazónicos: A participação indígena na produção de conhecimento cartográfico e geográfico jesuíta na Ásia e na América
}

\begin{abstract}
Resumo
No estudo da produção cartográfica jesuíta nas Américas, a contribuição indígena tem sido difícil de examinar e, como resultado, tradicionalmente obliterada. A situação da produção da ciência jesuíta na Ásia é, no entanto, completamente diferente, porque a discussão tem lidado com o grau de influência mútua entre a comunidade missionária Europeia e a intelligentsia local. A comparação entre os dois empreendimentos missionários, com uma ênfase especial sobre os jesuítas na China e na Amazônia espanhola, vai nos ajudar a situar melhor a medida em que as sociedades nativas, chinêsas ou amazônicas, forneceram um tipo de conhecimento que foi considerado vital e necessário para a produção de conhecimento geográfico e cartográfico entre as comunidades jesuítas nessas partes do globo. Assim, o principal objetivo é ressaltar a participação indígena no caso da produção cartográfica e geográfica dos jesuítas na Amazônia colonial.
\end{abstract}

Palavras-chave: cartografia, índios, jesuítas, Amazônia, China.

Este artículo tiene por objetivo dar una mirada general y comparativa a los mecanismos y procesos que permitieron a los jesuitas cartografiar los territorios misioneros ubicados en los extremos o fronteras de su empresa evangélica, es decir, América y Asia. En particular, se pondrá énfasis en el aporte de las sociedades locales a la producción de conocimiento elaborado por los misioneros llegados de Europa. Esto es importante tanto para el estudio de la producción científica jesuita en la Edad Moderna como para el análisis de la historia de la ciencia en la América Latina colonial. En su condición de sociedad transnacional, cualquier aproximación a la ciencia jesuita requiere romper las divisiones que tradicionalmente definen el estudio de fenómenos históricos, en especial aquellos que se concentran alrededor de los espacios 
nacionales e incluso continentales. Asimismo, esta visión comparativa nos permitirá resaltar que, así como la literatura sobre la ciencia jesuita en Asia ha ido poniendo mayor énfasis en la contribución de la comunidad letrada local, en el caso de América la historiografía sobre la cartografía y geografía jesuitas debe enfocarse en los elementos y estructuras que permiten sostener que los nativos americanos también estuvieron involucrados en la acumulación y producción de conocimiento por parte de los agentes jesuitas que vinieron de Europa.

Los miembros de la Compañía de Jesús fueron, y continúan siendo, parte de una empresa global. Similar a otras órdenes regulares, los jesuitas constituyen una organización religiosa esparcida por todo el orbe y que responde a los mandatos directos del General Superior de la orden en Roma. A su vez, los orígenes globales de los jesuitas están íntimamente ligados a sus tempranos orígenes como parte de los primeros agentes de la Iglesia contrarreformista. Fundada por el español Ignacio de Loyola en 1534 y aprobada por Roma en 1540, la Compañía desempeñó un rol importante en la campaña de la Iglesia post-tridentina que buscó defender y renovar los principios del catolicismo romano y evitar los errores que llevaron al surgimiento de protestantismo. Siguiendo el ejemplo de las órdenes religiosas del medioevo tardío como los franciscanos y los dominicos, los jesuitas fueron desde su incepción formados para ser parte del mundo por medio de la fundación de dos instituciones principales que les permitieron establecer relaciones cercanas con el resto de la sociedad. Mientras que los colegios se convertirían en el motor principal que permitió a la Compañía reclutar miembros de las élites locales en zonas urbanas, las misiones fueron establecidas con el objetivo de llevar su presencia a las regiones más periféricas del planeta.

Los colegios constituyeron el escenario ideal donde los jesuitas acumularían sus conocimientos relacionados a la cartografía. Andrés Prieto señaló, por ejemplo, que la "participación de los jesuitas en pedagogía los obligó a sistematizar su relación con la cultura y el aprendizaje" (2011: 3). Esta sistematización se tradujo en la elaboración de un currículo estándar para los colegios jesuitas alrededor del mundo, la "Ratio Studiorum" de 1586, la cual organizaba la educación en los colegios de la Compañía en cuatro campos: gramática, retórica, teología y filosofía. Los cursos de filosofía, de acuerdo a Benjamin Elman, "se extendían por un período de tres años e incluían lógica, ética, física y matemáticas (la cual incluía astronomía)" (2005: 88)². La formación jesuita, de este modo, incorporaba el estudio de las matemáticas y de la astronomía, siendo la cartografía un subproducto de éstas. Aunque el grado de importancia de la cartografía dentro de la formación académica

A no ser que se indique lo contrario, todas las traducciones incluidas en este artículo son mías. 
jesuita es debatible 3 , lo cierto es que los padres de la Compañía que eran enviados como misioneros a los rincones más alejados del orbe llevaban consigo los elementos necesarios para la producción de mapas, los cuales se podían convertir en una ayuda importantísima en las misiones puesto que les permitía localizar las diversas poblaciones que eran el objetivo de su empresa evangelizadora.

Ciertamente, la producción cartográfica jesuita respondía a circunstancias específicas acaecidas en los lugares donde se ponía en práctica. Sin embargo, el hecho de que su formación académica fue estandarizada y que su práctica derivó en la producción del mismo elemento -mapas-, hace necesario que el análisis de la cartografía jesuita sea comparativo. En ese sentido, este artículo se concentrará en los mapas y textos geográficos producidos por misioneros jesuitas en América y en Asia. Esta comparación nos ayudará a resolver una de las más importantes aseveraciones propuestas en relación a la cartografía, pero también a la producción científica en general, de los miembros de la Compañía, a saber, el aspecto colaborativo de la cartografía y geografía jesuitas en ambos extremos de su empresa evangélica.

Investigadores de las actividades científicas jesuitas en China han enfatizado que la producción cartográfica de los misioneros llegados de Europa dependió, en diversos grados, del corpus de conocimiento producido por académicos locales. Lo que yo encuentro problemático es que, como discutiremos a continuación, se quiera ver en esto una situación de excepcionalidad. Ciertamente, el tipo de fuentes históricas, en general escritas, ayudan al investigador de la ciencia jesuita en Asia a proveer ese tipo de conclusiones. En Sudamérica, sin embargo, a pesar de la falta de escritura entre las sociedades indígenas que interactuaban con los jesuitas, es posible encontrar, en los mismos relatos y correspondencia de los misioneros, indicios que nos llevan a concluir que, al igual que en China, las sociedades nativas contribuyeron a la acumulación y producción del conocimiento cartográfico y geográfico que los misioneros jesuitas elaboraron sobre la Amazonía en particular. De esta manera, este artículo propone que una comparación entre las literaturas sobre ciencia jesuita tanto en Asia como en América es indispensable para situar la problemática de la participación nativa en la producción científica jesuita y para hacer de América un sitio que no solamente recibió sino que produjo ciencia.

\footnotetext{
Por un lado, David Buisseret señaló que la Ratio Studiorum "enfatizaba las ciencias naturales, particularmente la cosmografía y la cartografía" y que los jesuitas fueron justamente conocidos "por sus estudios de las ciencias naturales" (2007: 1148). Por otro lado, Lesley B. Cormack indicó que a pesar de la inclusión de la geografía en el currículo jesuita alrededor del siglo diecisiete y de los constantes viajes ejecutados por miembros de dicha orden, "no existe una evidencia clara señalando que los mapas hayan sido una parte importante de dicho currículo" (2007: 630).
} 


\section{Cartografía jesuita en China: Ricci, Verbiest y el "Atlas Kangxi"}

En el caso de China, la historiografía ha paulatinamente ido otorgando una menor importancia al rol tradicional que había sido adscrito a la Compañía de Jesús como la fuerza motora que cambió y mejoró el supuesto nivel de atraso tanto de la cartografía como de la astronomía china. La imagen tradicional, que derivó de los mismos relatos de viajes jesuitas, era una en la cual los misioneros europeos eran descritos como "maestros y consejeros en China", quienes, además, "nunca habían estudiado la ciencia china, la cual ellos tendían a menospreciar" (Jami, 1999: 417). Joseph Needham, al contrario, argumentó que "la llegada de los jesuitas de ninguna manera fue (como ha sido recurrentemente hecho aparecer) una bendición sin parangón para la ciencia china". Más bien, él señaló que la participación jesuita en el desarrollo de la astronomía china demuestra "el mutuo impacto del pensamiento chino y el occidental" (1996: 283). De esta manera, Needham inició una explicación académica que indicaba que los misioneros de la Compañía vinieron a China no solo como maestros sino también como estudiantes del conocimiento científico chino.

Los jesuitas llegaron a China en el último cuarto del siglo dieciséis, durante los últimos tiempos de la dinastía Ming (1368-1644). Ellos llegaron financiados por la Corona portuguesa. Lo que ahora conocemos como el continente de Asia, excluyendo las Filipinas, se asumió como si fuera perteneciente al área de influencia lusitana de acuerdo al Tratado de Tordesillas de 1494, el cual había establecido por primera vez las zonas de control de las Coronas de Castilla y de Portugal alrededor del globo. De este modo, los jesuitas enviados a China fueron "entrenados en los mejores colegios de la Compañía ubicados en Coímbra y Évora", los cuales, junto al colegio jesuita de Roma, "ofrecían la mejor educación tanto en matemáticas como en ciencias naturales entonces disponible en Europa" (Elman, 2005: 87-107). Debido a su formación científica, los jesuitas demostraron, desde su llegada a China, un interés en "comprender la geografía de las tierras en las cuales estaban trabajando" (Foss, 1988: 210). Uno de esos científicos jesuitas fue el italiano Mateo Ricci, quien perteneció a un reducido grupo de "extranjeros" que acompañaron a la mayoría de jesuitas portugueses en China.

La figura del padre Ricci ha recibido considerable atención no solo debido a haber sido uno de los fundadores de la empresa jesuita en el lejano oriente sino también, dentro del campo de la historia de la cartografía, debido a los famosos mapamundis que produjo durante su estadía en aquellas tierras. En 1584, un año luego de su arribo, Ricci elaboró su primera "versión china de un mapamundi europeo, el cual él había traído consigo" (Foss, 1988: 211). Durante las siguientes décadas, Ricci continuó produciendo nuevas y mejora- 
das versiones de su mapa del mundo. Algo relevante acerca de su producción cartográfica lo constituyen las fuentes que el jesuita utilizó. De acuerdo a sus escritos, sabemos que Ricci poseía no solo "las obras de Ortelius y de Gerard Mercator", sino también el mapa comprehensivo de Lo Hung-sien de 1541 así como otros mapamundis chinos que habían sido reimprimidos en 1555 (Foss, 1988: 211). De este modo, a pesar de su formación europea y de su acceso a mapas occidentales, los mapamundis de Ricci dependieron también del conocimiento acumulado y producido por cartógrafos y geógrafos chinos.

Por medio de sus mapamundis, Ricci proveyó una imagen occidental del globo terráqueo a los letrados chinos. El impacto del trabajo del jesuita italiano en el conocimiento geográfico chino, de acuerdo a John D. Witek, "no deja lugar a dudas". Ricci no solo introdujo en la comunidad científica local "el uso de los meridianos" sino que tradujo al chino "más de mil términos, muchos de los cuales son usados comúnmente hasta el día de hoy tanto por chinos como por japoneses y coreanos" (1988: 71). De esta manera, los cartógrafos chinos pudieron obtener de los mapas de Ricci "un conocimiento considerable de su mundo exterior" (Foss, 1988: 214). Asimismo, el jesuita italiano colocó a China en el centro de sus mapamundis, "otorgando de esa manera a los chinos su tradicional sitial como el 'reino del medio'" (Foss, 1988: 211). Todos estos elementos, cuyo objetivo fue establecer relaciones más cercanas entre los jesuitas y los letrados chinos, se entienden mejor dentro del "método de acomodación" de Ricci. De acuerdo a Witek, este método implicó "el intento de Ricci por entender la civilización china en sus propios términos", es decir, que "solo el respeto a la cultura local podía permitirles la entrada a China" (1988: 65-64). Aunque Cordell Yee ha señalado que los mapamundis del jesuita italiano no fueron adoptados en el conocimiento geográfico chino en demasía (1994: 177), el hecho relevante es el objetivo de Ricci al combinar tanto fuentes europeas como asiáticas. Así, y a pesar de que no haya influenciado grandemente a sus contemporáneos chinos, la producción cartográfica del jesuita italiano fue en realidad colaborativa antes que meramente "occidental".

El flamenco Ferdinand Verbiest fue otro cartógrafo jesuita que formó parte de la misión de la Compañía a China. Durante los primeros años de la dinastía Qing (1644-1911), Verbiest se convirtió en uno de los jesuitas que continuó produciendo mapamundis que fueron básicamente consumidos por la comunidad letrada china y los oficiales de la corte Qing. En 1647 él presentó al Emperador Kangxi su mapamundi titulado Kunyu quantu o "mapa completo del mundo" (Song y Demattè, 2007: 71). Siguiendo "la tradición establecida por Ricci", Verbiest delineó su mapa del mundo de tal manera que "el hemisferio occidental está a la derecha y el oriental, a la izquierda". De acuerdo a Gang Song y Paola Demattè, esta manera de representar el globo expresó justamente, de parte de Verbiest, un medio de acomodarse "a la tradición china según la cual dicho territorio estaba situado en el cen- 
tro del mundo". Además, el jesuita flamenco reforzó dicha acomodación al colocar el meridiano principal de su mapamundi sobre "Beijing, capital del imperio Qing" (2007: 75).

Sobre la demarcación de los contornos del territorio chino en el mapamundi de Verbiest, Song y Demattè notaron que aunque dicha delineación estaba relacionada hasta cierto punto con lo que había sido representado en mapamundis jesuitas anteriores, como el de Ricci, "de ninguna manera se trataba de una copia exacta". Al contrario, parece plausible afirmar que "Verbiest utilizó fuentes chinas recientes, así como información actualizada de expertos locales sobre la situación del Asia oriental y suroriental". Entre aquellas fuentes nativas chinas usadas por el jesuita flamenco, se encontraban sobre todo "los datos y mapas incluidos en las gacetas provinciales" (Song y Demattè, 2007: 81). Estas gacetas, de acuerdo a Yee, fueron "compendios de información sobre las unidades administrativas" que conformaban el imperio y que incluían secciones sobre historia local, literatura y geografía (1994: 188). Paradójicamente, los mapas que aparecían en estas gacetas provinciales parecen constituir los menos influenciados por las técnicas y métodos cartográficos de los jesuitas (Yee, 1994: 188-191). En este sentido, Verbiest vino a depender precisamente de aquellas fuentes que fueron más ajenas a la comunidad científica jesuita. Esto demuestra que los miembros de la Compañía en China buscaron no el tipo de fuentes que validaran sino aquellas que complementaran su propio conocimiento geográfico y cartográfico. Asimismo, es importante indicar que, a pesar del uso de fuentes locales, la influencia de Verbiest entre los letrados chinos parece haber sido más bien limitada. Tal como el caso de Ricci, el mapamundi del jesuita flamenco fue solo selectivamente usado por los geógrafos chinos y solo influenció "a aquellos quienes estaban cercanamente asociados con los misioneros" (Song y Demattè, 2007: 83).

Para fines del siglo diecisiete y para el dieciocho, el estudio de la producción cartográfica de la Compañía en China ha estado mayormente enfocado en los mapas elaborados por los miembros de la misión jesuita francesa, encabezada por el padre Jean de Fontaney, que arribó a Beijing en 1685. Mientras que los primeros misioneros de la Compañía llegados de Portugal habían mantenido relaciones cercanas a la comunidad letrada china, los jesuitas franceses "dependieron casi exclusivamente del patronazgo imperial de los manchúes" (Elman, 2005: 134-148). Esta nueva relación hizo que los jesuitas en China, más que nunca antes, se convirtieran en un grupo especializado de astrónomos y geógrafos cuyas actividades perseguían "de manera creciente las necesidades de la burocracia Qing antes que los objetivos de la iglesia" (Elman, 2005: 133). Este grupo de misioneros había sido precisamente enviado por el rey de Francia, Luis XIV, con el objetivo de establecer lazos con las autoridades imperiales manchúes. De acuerdo a Han Qi, la misión de estos jesuitas, conocidos como los "matemáticos del Rey", era no solo evangelizar 
sino también hacer de China un objeto de estudio y, en particular, realizar "observaciones astronómicas tal como ellos lo habían discutido previamente con astrónomos franceses". Entonces, el objetivo general de estos jesuitas era "mejorar el conocimiento científico" sobre China mientras se "ensalzaba la gloria del Rey de Francia" (2001: 137).

La contribución más importante de la misión jesuita francesa fue el Atlas Kangxi ${ }^{4}$. Esta colección de mapas debe ser entendida como una empresa colaborativa que involucró tanto intereses imperiales de los manchúes como los objetivos de los misioneros llegados de Francia. Por un lado, Theodore Foss señaló que, alrededor de la primera década del siglo dieciocho, "un genuino interés por obtener una representación geográfica exacta de China se hizo bastante evidente al emperador Kangxi debido a la expansión rápida que estaba experimentando el imperio Qing" (1988: 222). En este contexto, los conocimientos astronómicos jesuitas, así como sus métodos de exploración y medición geodésicos, se hicieron indispensables para los objetivos y necesidades del emperador chino, lo cual, a la larga, ayudaría a que la dinastía Qing legitimizara sus reclamos territoriales en el ámbito internacional (Hostetler, 2009: 118). Las mediciones y exploraciones habían empezado, extraoficialmente, en 1700 cuando las constantes inundaciones de los ríos que rodeaban Beijing convencieron al emperador que aquella región requería ser explorada y cartografiada por los jesuitas. Las mediciones oficiales se iniciaron en 1708 cuando los misioneros empezaron a explorar "el área que rodeaba el norte de la gran muralla". Luego, el emperador ordenó a los jesuitas que "se dividieran en múltiples compañías" para que así se agilizaran las exploraciones del territorio correspondiente a las provincias controladas desde Beijing, las cuales culminarían en 1717 (Foss, 1988: 223-227). Al año siguiente, todos los mapas producidos por los misioneros "fueron compilados en Beijing por el jesuita Pierre Jartoux en un atlas", el cual fue dado al emperador Kangxi y "publicado en chino como Guangyu guanlan tu (Atlas completo de los territorios imperiales)" (Reed, 2007: 20).

Por otro lado, mientras que la corte china y el conocimiento de su multifacético y extenso territorio se vieron beneficiados por los métodos de medición y por el saber geográfico de la misión jesuita francesa, el Atlas Kangxi también sirvió a los intereses europeos que querían expandir su propio conocimiento sobre China. Los misioneros jesuitas enviados al extremo oriente tenían lazos cercanos con las sociedades científicas europeas, en particular, con los mayores cartógrafos de Francia, con quienes mantenían en común un profundo interés en "cuestiones geográficas" (Foss 1988: 221).

Para una revisión del Atlas Kangxi, así como de las exploraciones y mediciones que lo hicieron posible, ver Hostetler (2009: 93-132). 
En efecto, una copia del Atlas Kangxi fue simultáneamente enviada a París, donde se convirtió en la fuente principal de la muy popular "Descripción de China" escrita por el jesuita Jean-Baptiste Du Halde y publicada en 1735 (Reed, 2007: 20). De esta manera, y tal como lo indicó Foss, el Atlas Kangxi participó de ambos mundos puesto que los exploradores jesuitas "no solo proveyeron a la corte imperial china con un atlas" de sus territorios, sino que su información tanto geodésica como cartográfica "fue enviada a Europa y fue transformada en un atlas europeo de China también" (1988: 222). El siglo dieciocho, en general, presenció un incremento en el contacto entre los jesuitas de China y la comunidad académica en Francia, en especial, con aquellos pertenecientes a la Academia Real de las Ciencias, adonde enviaron muchas de sus observaciones astronómicas y mediciones geodésicas efectuadas en el lejano oriente. Estos informes llegaron a ser publicados en los órganos oficiales de la Academia, la cual también incluyó a algunos de los misioneros como miembros correspondientes -tal es el caso de Antoine Gaubil y Pierre Le Chéron, estudiosos de la astronomía y de la botánica en China, respectivamente (Qi, 2001: 141)-. Pero la contribución de la misión jesuita francesa a los intereses europeos estuvo no solo circunscrita a las observaciones que se hicieron sobre los eclipses, cometas, latitudes y longitudes en China, sino también a las investigaciones que se realizaron sobre la astronomía china tradicional (Qi, 2001: 142-143).

El hecho de que los miembros de la Compañía estuvieron también interesados en recuperar y aprender las técnicas indígenas chinas está reflejado en los mismos métodos e instrumentos que usaron para hacer sus mediciones en territorio asiático. Por un lado, los jesuitas usaron toda la ciencia cartográfica que ellos habían aprendido como parte de su formación académica en sus colegios en Europa. Ellos hicieron uso, por ejemplo, de instrumentos como cuadrantes, compases y péndulos para calcular las latitudes y longitudes de diversos lugares. Luego, esas coordenadas serían trazadas mediante el método de triangulación, lo cual permitió que aquellos diversos puntos pudieran ser localizados e interconectados sobre un mapa. Como Foss indicó, el Atlas Kangxi fue "el primero de los grandes atlas que fue resultado de mediciones obtenidas mediante este método" de la triangulación. Sin embargo, como él mismo lo deja señalado, sin "el uso de las exploraciones y de la cartografía tradicional china, los jesuitas no habrían podido completar sus mediciones" (1998: 228-229). Entonces, la mejor manera de entender el proyecto del Atlas Kangxi es concebirlo como resultado de una yuxtaposición tanto de elementos "científicos" europeos como de la "tradición" cartográfica china (Hostetler, 2009: 116). Por ejemplo, las mediciones que los jesuitas ejecutaron en la China manchú vino a depender de fuentes nativas especialmente en aquellas áreas que fueron inaccesibles para los misioneros, tales como el Tíbet, Japón, Corea y los márgenes de Manchuria, -todas las cuales fueron incluidas en el atlas (Foss 1988: 230). Además, los jesuitas también recibie- 
ron apoyo de "estudiosos, ayudantes y asistentes chinos y manchúes, los cuales colaboraron con ellos durante las mediciones" (Foss 1998: 233). Así, el Atlas Kangxi de 1718 y las exploraciones y mediciones de China que se desarrollaron entre 1708 y 1718 pueden ser ciertamente consideradas como fruto de una empresa corporativa, la cual "le debe tanto a la cartografía tradicional china [...] como al conocimiento cartográfico de los científicos jesuitas" (Foss, 1988: 240-230).

De esta manera, la cartografía jesuita en China ha sido tradicionalmente explicada como un proyecto colaborativo que involucró intereses tanto de la comunidad letrada local, de los misioneros jesuitas y de la corte imperial china. Que los jesuitas hayan tenido una influencia de hecho o decisiva en la producción científica y cartográfica china es, como hemos visto, debatible. Sin embargo, los estudiosos ciertamente están de acuerdo en enfatizar la naturaleza colaborativa de la producción científica jesuita en el Asia oriental. El único punto débil de este tipo de interpretación es el hecho de que se tiende a presentar un punto de vista excepcionalista en relación a la ciencia jesuita en China, como si esta "colaboración" entre actores e intereses foráneos e indígenas solo hubiera ocurrido en aquel territorio. Por ejemplo, Benjamin Elman argumentó que los miembros de la Compañía enviados a China no impusieron, sino que adoptaron un "método de acomodación" al estilo de vida chino, incluyendo su conocimiento científico. Esto permitió que los jesuitas encajaran todo lo chino dentro de los parámetros católicos y occidentales (2005: 112-116). Más importante, Elman señaló que los misioneros jesuitas "generalmente no emplearon [el método de acomodación] en Japón, India, Persia, o el sudeste asiático, ni mucho menos en el Nuevo Mundo" (2005: xxxii). Sin embargo, los estudios sobre la producción científica de los miembros de la Compañía en territorio americano han justamente empezado a enfatizar que los misioneros llegados de Europa se apropiaron también del conocimiento y técnicas indígenas, creando en consecuencia una situación en la cual "los maestros jesuitas se convirtieron en estudiantes mientras que los estudiantes indígenas se transformaron en sus maestros" (Prieto, 2011: 33). Como resultado, la producción científica jesuita entre los pueblos indígenas "incultos" del norte y sur de América parece más bien haber seguido el mismo patrón colaborativo que experimentó la ciencia jesuita entre las élites "letradas" chinas.

\section{Cartografía jesuita en América: Kino, Fritz y los bogas amazónicos}

Los primeros misioneros de la Compañía que llegaron a América, igual que en el caso chino, pertenecían a la provincia jesuita portuguesa. Ellos arribaron a Brasil en 1549. Luego, otro contingente misionero de la provincia 
jesuita española llegó a Florida (1566), Perú (1568) y México (1572)5. Aunque la misión jesuita en Florida solo permaneció hasta 1572, Perú y México se convirtieron en los principales centros a partir de los cuales la Compañía de Jesús expandió su empresa misionera por todo el norte y el sur de América. De acuerdo a Andrés Prieto, la empresa jesuita americana presentó una particularidad. Más que "direccionar recursos materiales y humanos a los colegios y universidades manejados por la orden", como ocurría en Europa, "en América los jesuitas se concentraron en la evangelización de las comunidades nativas" (2011: 4). Esta situación significó que mientras en Europa y, como hemos mencionado, China, la producción científica jesuita estuvo fuertemente relacionada al mejoramiento de la reputación de los miembros de la Compañía entre los grupos de poder locales y las comunidades letradas, la ciencia misionera en América estuvo asociada al entendimiento, explicación y modificación de los conocimientos y tecnologías indígenas como parte de la empresa evangelizadora jesuita (Prieto, 2011: 4).

El problema con la historiografía de la cartografía jesuita, y de la ciencia jesuita en general, en América, ha sido justamente su tradicional menosprecio por examinar la más bien cercana relación que hubo entre el conocimiento indígena y el jesuita, o, si se quiere, la situación de colaboración o hasta de dependencia en que usualmente se encontraron los misioneros con respecto a la apropiación y utilización del saber amerindio. Por ejemplo, en el caso de dos estudiosos usualmente considerados los fundadores del estudio de la cartografía jesuita americana, los padres Guillermo Furlong y Ernest Burrus, ellos simplemente no hallaron ningún ápice de la naturaleza colaborativa en la producción de mapas jesuitas en América. Se debe enfatizar, sin embargo, que los trabajos de Furlong y Burrus trajeron consigo un cambio importante a la historiografía latinoamericana puesto que, hasta entonces, los estudios se habían básicamente enfocado en el aspecto político y evangelizador de la Compañía de Jesús, pero no en su producción científica. En este sentido, Burrus argumentó que la literatura sobre la provincia jesuita de México había prácticamente silenciado "otras fases del apostolado mexicano jesuita", en particular, "los esfuerzos científicos producidos tanto en sus centros misioneros como en sus colegios" (1967: 1*). El caso específico de la producción cartográfica jesuita en México, de acuerdo a Burrus, había sido, "un tema hasta entonces casi completamente menospreciado" (1967: 2*). Asimismo, en su estudio sobre los mapas jesuitas de las misiones del Paraguay, el padre Furlong mencionó que no existe región en las Américas donde los jesuitas no hayan destacado

La siguiente discusión sobre la producción científica jesuita en América está básicamente concentrada en los territorios imperiales de Portugal y España. De este modo, no incluye lo relacionado a la presencia jesuita en Nueva Francia y Maryland. 
por sus esfuerzos y logros en el estudio y práctica de la cartografía (1936: 5). De este modo, estos primeros estudios prepararon el camino no solo para el establecimiento de un nuevo objeto de estudio historiográfico sino también para enfatizar que los jesuitas merecían recibir una mayor atención por parte de los investigadores, puesto que estos misioneros se encontraban entre los más importantes cartógrafos del continente americano en tiempos modernos.

Parecido a los estudios sobre Ricci o Verbiest en China, en América se ha tendido a examinar casos particulares de cartógrafos jesuitas y los mapas de su producción. Una diferencia importante, para el caso americano, es que los jesuitas no estuvieron aparentemente interesados en la producción de mapamundis sino en lo que se podría denominar "mapas regionales", ya sean topográficos o propiamente geográficos. Dos personajes han tradicionalmente monopolizado los análisis sobre la cartografía jesuita americana: Eusebio Kino y sus mapas de la Baja California y Nueva España, y Samuel Fritz y sus mapas del río Amazonas. Kino laboró en las misiones que la Compañía había establecido en la Baja California, Sonora y Arizona entre 1683 y 1711. Su formación académica en el colegio jesuita de Ingolstadt, Alemania, incluyó clases sobre matemáticas y ciencias naturales dadas por renombrados cartógrafos y geógrafos jesuitas como Adam Aigenler y Heinrich Scherer. Mientras que los jesuitas enviados a China tuvieron primero que pasar por Portugal antes de embarcarse hacia el extremo oriente, Kino se mudó a Sevilla, donde continuaría sus estudios sobre matemáticas y cartografía en el Colegio de San Hermenegildo, antes de partir para México (Burrus, 1965: 3-4). En el sur de España, Kino también tendría la oportunidad de realizar observaciones astronómicas y de fabricar instrumentos de medición -como un reloj solar que dio como presente al General de los jesuitas en España, Tirso Molina (Sierra, 1944: 308).

La producción cartográfica más reconocida de Kino es su "Paso por tierra a California" de 1701. De acuerdo a Burrus, este mapa fue el resultado de los tres años que el jesuita pasó explorando aquella región. Kino estuvo interesado en determinar la "insularidad o peninsularidad de California". Con este mapa, él finalmente pudo demostrar que la Baja California no era una isla, como se creía hasta entonces, sino una península (1965: 17). Sin embargo, Burrus, siguiendo ciertamente las propias palabras del antiguo misionero, no prestó atención a la posibilidad de que el conocimiento y participación indígenas hubieran facilitado la labor del cartógrafo jesuita. Por un lado, Burrus notó que Kino usaba mapamundis con fines evangelizadores:

en un mapa del mundo [Kino] les indicaba [a los indios de San Xavier del Bac] las tierras, los ríos y los mares que los misioneros había navegado desde zonas lejanas para traerles el conocimiento redentor 
de nuestra sante fe [...] Yo les mostré sobre un mapamundi, cómo los españoles y la fe católica habían llegado por mar a Vera Cruz, y de allí alcanzaron Puebla, Ciudad de México, Guadalajara, Sinaloa, Sonora y, ahora, Nuestra Señora de los Dolores de Cosari, su propia tierra, el país de los pimas, donde ya habían muchos bautizados (1965: 13).

De esta manera, se entiende que Kino comprendió que el valor de un mapa radicaba no solo en su descripción y delineación geográficas sino también en su mensaje pedagógico y evangelizador.

Por el otro lado, Kino simplemente no fue capaz de incluir a los nativos del noroeste mexicano como parte de la planificación y elaboración de su propio conocimiento geográfico y cartográfico de dicha zona. Es decir, él sí pudo representar a los indios como sujetos capaces de recibir conocimiento, ya sea geográfico o evangélico, por medio de mapas, pero no como sujetos capaces de construir y colaborar en la producción del conocimiento cartográfico por parte de los padres jesuitas. Por ejemplo, en relación a sus exploraciones y técnicas de medición, Kino mencionó que "gracias a Su Majestad Divina, luego de varias expediciones, y de tres en particular [...] yo descubrí con todos sus detalles, certeza y evidencia, por medio de una aguja magnética y un astrolabio en mano, que California no es una isla sino una península o istmo" (Burrus, 1965: 15). Kino, entonces, se presentaba a sí mismo como "el" descubridor, enfatizando de esta manera su estatus como hombre de ciencia debido al uso de instrumentos que le permitieron tomar las medidas necesarias para sus observaciones astronómicas y para su mapas. Esto, a su vez, le permitió al jesuita obviar el hecho de que él estuvo explorando un área habitada y cuyos pobladores pudieron ciertamente, si no proveerle de información geográfica, al menos guiarlo durante sus excursiones californianas.

Para el caso sudamericano, el cartógrafo más estudiado ha sido Samuel Fritz, reconocido por sus mapas del río Amazonas. Formado como jesuita en Europa, Fritz atendió la Universidad de Olomouc, actual República Checa, para luego ser enviado como misionero a Sudamérica. Él trabajó en las misiones de Maynas, pertenecientes a la provincia jesuita de Quito y localizadas en la Amazonía occidental, entre 1685 y 1723. Fritz es reconocido, en particular, por su "El gran río Marañon o Amazonas", mapa del río del mismo nombre grabado en 1707. Este mapa ha recibido atención tanto por su agenda política, su mensaje evangélico y su circulación transatlántica (Dias, 2012: 95-116; Langer, 2009: 79-90; Latorre, 1988: 37-47; Lucero, 2004: 42-88). Sin embargo, nada se ha dicho sobre la posibilidad de la participación de nativos amazónicos en la producción cartográfica y geográfica de Fritz. André Ferrand de Almeida, por ejemplo, ha ayudado a elucidar algunas de las primeras producciones cartográficas 
de Fritz, asignándole en particular la autoría de dos mapas manuscritos del Amazonas, hasta entonces considerados anónimos, elaborados en 1689 y 1690 (2003a: 113-119). Almeida también indicó que el mapa amazónico de Fritz fue reproducido en muchas ocasiones y tuvo una circulación considerable entre la burocracia española y la comunidad jesuita europea. Sin embargo, parecido a los estudios sobre la repercusión de los mapamundis jesuitas en la cartografía china, el mapa de Fritz no habría provocado un cambio importante en la manera como los cartógrafos europeos del siglo XVIII delineaban y demarcaban el curso del río Amazonas en sus mapas (2003b: 133-153).

A pesar de sus obvias contribuciones, el análisis que Almeida hizo sobre el mapa del Amazonas de Fritz todavía se inscribe dentro de la narrativa tradicional que indica que la producción científica y técnica jesuita derivó exclusivamente de su formación académica, ya sea en Europa o en América. Un primer obstáculo que se debe sobrepasar es el hecho de que, como David Buisseret lo señaló hace ya algunos años, la instrucción intelectual de los cartógrafos jesuitas americanos es un tema poco conocido (1997: 114). Al ser su formación poco conocida, los factores que pudieron haber participado de ella, incluyendo la contribución indígena, constituye también un tema poco explorado. Al respecto, Anne Godlewska notó que los vastos territorios que los misioneros ocupaban en el Nuevo Mundo hicieron que los jesuitas tuvieran que depender o recurrir a fuentes nativas para poder completar sus exploraciones geográficas. Los nombres y locación de las sociedades indígenas, por ejemplo, van siempre mencionados e indicados en la superficie de los mapas producidos por los misioneros. Por ello, "en algunos de sus mapas [...] hay una clara presencia indígena" (1997: 107). Esta "presencia indígena" ha sido subrayada, de cierto modo, por algunos investigadores. Almeida, por ejemplo, indicó que la profusión de nombres de las diferentes comunidades nativas en el mapa de Fritz de 1707 expresaba "la gran diversidad de la población indígena en la cuenca amazónica" (2003b: 138). Asimismo, Burrus señaló que en los mapas de Kino de la Baja California y del norte de México, "el elemento humano aparece en primer plano. No son ni las montañas, ni los ríos, ni la vasta extensión de los llanos [...] el principal interés de Kino; es la gente" (1965: 13). Sin embargo, ni Burrus ni Almeida tomaron en consideración el hecho de que aquellos nombres y sitios indígenas en los mapas misioneros de las Américas hayan podido ser resultado no solo de exploraciones y formulaciones unilaterales por parte de los jesuitas sino tambien de proyectos colaborativos entre los misioneros y los nativos amazónicos, -similar a lo que ocurría entre los padres jesuitas y los letrados chinos en Asia.

La verificación de la participación indígena en la producción científica y catográfica de los jesuitas europeos en China ha sido facilitada por la 
presencia de registros escritos legados por científicos y letrados chinos de las dinastías Ming y Qing. En el caso americano, las sociedades indígenas del noroeste de México y de la Amazonía simplemente no han dejado ningún documento escrito a partir del cual los estudiosos pudieran fehaciente y concretamente comprobar la existencia de conocimientos cartográficos y geográficos indígenas y su utilización por la comunidad jesuita llegada de Europa. Sin embargo, como Neil Whitehead dejó indicado, "cuando se discute la incorporación de las ideas espaciales indígenas en los mapas europeos, es importante tomar en cuenta que la información geográfica puede ser transmitida por medios distintos a la representación gráfica, tales como gestos, palabras, canciones y otros" (1998: 322). Al respecto, en los últimos años ha habido algunos intentos por examinar la contribución indígena a la cartografía jesuita americana. Glória Kok, por ejemplo, enfatizó el hecho de que tanto los misioneros jesuitas como los exploradores conocidos como bandeirantes incursionaron en el interior del territorio meridional brasileño gracias a los caminos y rutas que ya habían sido abiertos por indios guaraníes (2009: 94).

Artur Barcelos y Norberto Levinton llevan el caso un poco más adelante y examinan mapas indígenas que los guaraníes elaboraron y usaron como parte de los litigios para defender sus tierras en la región del río de la Plata después de la expulsión de la Compañía. Los materiales que ambos investigadores analizaron parecen ser tan raros y únicos que ni Barcelos ni Levinton se dieron cuenta de que estaban estudiando el mismo documento -el mapa del pueblo de La Cruz, ubicado en la banda izquierda del río Uruguay, actual Argentina, y fechado en 1784. Por un lado, Barcelos indicó que luego de 150 años de presencia jesuita en el área, los guaraníes aprendieron a utilizar "en defensa de sus intereses" el conocimiento cartográfico legado por los misioneros. Esos mapas no solo demuestran que los guaraníes conocieron "el uso de topónimos" y "la demarcación de limites espaciales" sino también el "uso práctico de la cartografía y su combinación con documentos oficiales" como parte de sus pleitos por tierras. De esta manera, los guaraníes llegaron a usar las mismas tácticas, tanto cartográficas como legales, que usaban los españoles para defender sus propiedades (2010: 13). Levinton, por otro lado, argumentó que "el dibujo básico" de dicho mapa "fue realizado por un jesuita", quien tuvo que emplear un conjunto de "instrumentos que exigían estudios de topografía, geodesia y matemáticas". Sin embargo, los guaraníes fueron ciertamente capaces de utilizar, copiar "varias veces" y reescribir "la trama básica" jesuita (2010: 588). Este caso demuestra la existencia de mapas indígenas que todavía se encuentran archivados, que todavía faltan por examinar y que merecen ser incluidos dentro de la narrativa historiográfica de la producción cartográfica sudamericana. Más importante, este mapa revela, hasta cierto punto, el 
carácter colaborativo nativo-misionero de la cartografía producida dentro del contexto de la empresa jesuita en América.

En el caso particular de la Amazonía, aunque los misioneros llegaron para "enseñar" a los nativos locales, ellos también "aprendieron" el saber indígena. Cuando exploraban y navegaban el Amazonas, los jesuitas actuaban más bien como novatos que dependían de guías o "indios bogas" que les ayudaran a reconocer el intrincado sistema de caminos y ríos amazónicos ${ }^{6}$. En este sentido, los mapas jesuitas no pueden ser considerados simplemente como una reflexión unilateral del punto de vista misionero. En el caso de Fritz, y de los misioneros de Maynas en general, no existe evidencia de que algún mapa o algún tipo de información geográfica indígena haya sido utilizado como fuente para realizar sus propias labores cartográficas. Sin embargo, si hubo una situación en la cual la exploración y navegación del Amazonas por el jesuita requirió la asistencia de los habitantes nativos fue justamente durante el famoso viaje que le permitió a Fritz recorrer la longitud de este río en 1689, la ida, y 1691, la vuelta, tiempo durante el cual el jesuita residió en los dominios amazónicos portugueses en el Pará.

Al comienzo de su viaje a Belém do Pará en 1689, Fritz fue primero guiado río abajo por "el cacique Mativa y diez yurimaguas", luego de partir desde la misión de Nuestra Señora de las Nieves de Yurimaguas el 3 de julio. Siete días después, Fritz dejó el pueblo de Yoaboni -ubicado cerca de la boca del río Yupurá y habitado por nativos ibanomas- "acompañado de pobladores de tal asiento". El 15 de julio, el jesuita arribó al pueblo de Cuchivaras, de donde partió nueve días después asistido por indios del pueblo. El 28, luego de atravesar la boca del río Negro, los cuchivaras y Fritz se cruzaron con una flota de indios tupinambarana cuyo cacique, Cumiarú, dio al jesuita "un indio boga" para que los llevase hasta la villa de Urubú. Fritz, gracias a la dirección y ayuda de muchos nativos amazónicos, consiguió finalmente contactar a la flota portuguesa en Urubú el 1 de agosto, y así fue finalmente conducido hasta Belém (Fritz, 1922: 63-64). De esta manera, en su trayecto hacia Pará en 1689, Fritz "nunca estuvo solo, siempre tenía guías" (Barcelos, 2013: 262).

Asimismo, cuando regresó desde Belém en 1691, Fritz no solo fue escoltado por un capitán portugués, siete soldados y un cirujano, sino también por "unos treinta y cinco indios remeros de varios pueblos". El 7 de septiembre la flota se detuvo cerca de la boca del río Negro, donde ellos

6 En el caso de las misiones jesuitas en América del Sur, Andrés Prieto argumentó que "la necesidad de supervivencia en lo que usualmente era un medio ambiente agresivo y poco familiar forzó a que los misioneros describieran, explicaran y utilizaran los recursos de la naturaleza y el conocimiento indígena acerca de ello" (2011: 4). 
se encontraron con un grupo de unos ochenta indios taromas y su cacique, Carabiana. Dos días después, la flota "dejó el río Negro acompañada de doce taromas". El 18, después de un corta estadía en el recientemente quemado pueblo de Cuchivaras, el capitán portugués "condujo encadenado a un cuchivara, que había sido recogido en el río, para que no se escapara y sirviera como guía". Cuatro días después, los taromas se escaparon y la expedición "se quedó sin guías". El 4 de octubre, después de pasar dos días en el pueblo de Yoaboni, de nativos ibanomas, los portugueses y Fritz continuaron con su periplo río arriba acompañados por el cacique local, Arimauana, y algunos de "sus hombres en dos pequeñas canoas". Luego de pasar por varios pueblos de los aizuares y de los yurimaguas, la expedición finalmente arribó a la misión de Nuestra Señora de las Nieves el 13 de octubre. Siete días después, los portugueses regresaron a Pará mientras que Fritz continuó su viaje hacia San Joaquín de Omaguas (Fritz, 1922: 69-78). De esta manera, el famoso viaje de Fritz, ida y vuelta por el río Amazonas, suena completamente diferente cuando incorpora la presencia de los nativos dentro de la narrativa. De hecho, la colaboración indígena fue la que hizo que el viaje transamazónico del jesuita fuera posible y, parafraseando a John Rennie Short, hizo que los misioneros de la Compañía fueran "menos exploradores, más viajeros, siguiendo rutas bien conocidas" en la Amazonía (2009: 77).

La extensión a partir de la cual debe entenderse la participación de los nativos amazónicos en las exploraciones jesuitas está fuera de debate. La colaboración en la producción científica y tecnológica es distinta y más difícil de evaluar. Artur Barcelos, por ejemplo, notó que gracias a los levantamientos que hizo durante su periplo transamazónico, Fritz "elaboró un mapa detallado de la red hidrográfica, localizando poblaciones indígenas, misiones, villas y ciudades españolas y portuguesas" (2013: 267). Pero, ¿se puede decir que los indígenas amazónicos colaboraron con dichos levantamientos o con la producción cartográfica del jesuita? Además de servir como guías durante sus viajes, los nativos también proveyeron la tecnología adecuada para los recorridos amazónicos de los misioneros. En agosto de 1707, Fritz estaba regresando de Quito con diez nuevos frailes para las misiones de Maynas. Ellos estaban navegando el Napo, río abajo, asistidos por un grupo de remeros nativos. Cuando la expedición se hallaba cerca de aportar en una margen del río, la fuerza de la corriente hizo que la barca donde viajaban los padres Andrés Cobos y Matías Laso se volteara. Sin embargo, "ayudados por los indios, quienes rápidamente llegaron a ayudarnos en sus pequeñas canoas, pudimos llegar a la orilla; y allí pasamos el día y la noche dando gracias a Dios por todo, especialmente los dos padres" (Fritz, 1922: 116). Canoas, con seguridad, fueron los medios de transporte más importantes en la Amazonía. Los viajes de los misioneros jesuitas por medio de sus numerosas vías fluviales vino a depender necesariamente de la 
experiencia, asistencia así como del equipamiento y tecnologías indígenas. Los jesuitas conocían de antemano la necesidad que tenían de contar con las canoas de los nativos que facilitaran su actividades evangelizadoras en el Amazonas. En un documento donde se enumeraban los deberes que debían cumplir los indios que moraban en el pueblo de Santiago de la Laguna, centro misionero ubicado cerca a la confluencia de los ríos Huallaga y Marañón, las autoridades jesuitas indicaron que:

Los curacas é yndios principales acudirán á todo lo que al padre cura se le ofreciere, como es hazer chagra, yglesia y casa del padre. Todas las semanas avrá mitayos yndios, que cuiden del sustento de el padre [... y y si el padre cura estuviere en parte de ríos, los curacas, y caziques le haran canoa para su menester?

De esta manera, las instrucciones dadas a los misioneros jesuitas en relación a las órdenes que debían hacer cumplir a los curacas de las comunidades bajo su cuidado incluían la asistencia de los nativos a los padres tanto en su subsistencia como en sus actividades propiamente misioneras. Neófitos en términos cristianos, los indios de la Laguna eran considerados expertos en otras áreas de importancia para la movilidad misionera amazónica, como la construcción de canoas. Asimismo, el jesuita Pablo Maroni indicó que en tiempos de inundación en el pueblo de San Joaquín de Omaguas, los nativos:

viven en pisos elevados hechos de corteza de árboles, y salen y entran en sus casas por medio de canoas, y no hay nada extraño en esto, puesto que su vida transcurre perpetuamente sobre los ríos y lagunas para pescar, y para remar, en cuyas artes ellos son más habilidosos que ninguna otra nación (Fritz, 1922: 50-51).

Entonces, sociedades fluviales como los omaguas, los yurimaguas, los ibanomas y los aizuares, entre otros, se convirtieron en compañeros necesarios y valiosos de las empresas y actividades misioneras jesuitas, en particular aquellas que permitieron que Samuel Fritz surcara las aguas del río Amazonas a fines del siglo XVII. La navegación y exploración de los bosques y ríos tropicales resultó, entonces, no solo de la voluntad de los jesuitas, novatos en asuntos amazónicos, sino, sobre todo, de la colaboración y de la tecnología provista por aquellos individuos cuya vida transcurría con la mayor tranquilidad y sapiencia en las aguas y tierras de la cuenca del Amazonas.

Angel María Manca, S.I., "Órdenes de los Provinciales y Visitadores, desde el Padre Hernando Cavero hasta el Padre [Martin] Iriarte," San Joaquín de Omaguas, 15 de mayo de 1752, en Archivo de la Compañía de Jesús de Quito, leg. 8, doc. 767, f. 2v. 


\section{Conclusión}

En relación a la naturaleza colaborativa que condujo a la participación indígena en la producción de conocimiento entre miembros de la Compañía, Benjamin Elman señaló que, a pesar de las políticas de "acomodación" que los jesuitas pusieron en práctica durante sus actividades científicas en China, hubo situaciones tensas entre los letrados chinos y los misioneros que llevaron a que cada partido buscara eliminar u ocultar la contribución del otro. Del lado de los jesuitas, esto significó que personajes como Ricci y Verbiest "trataron de substituir el contenido clásico [chino] de la investigación de las cosas del mundo con teorías europeas occidentales sobre los estudios de la naturaleza, lo cual posibilitaría que los chinos accedieran al concepto de lo celestial y aceptaran a la iglesia" (Elman, 2005: 113). A pesar de este intento por substituir u obliterar al otro, en este artículo hemos señalado cómo los investigadores han sostenido que la producción de conocimiento científico jesuita en Asia, en particular sobre la cartografía y geografía, estuvo asociada a relaciones de patronazgo y conexiones establecidas con intelectuales y oficiales de la corte china.

En el caso americano, la obliteración de la contribución indígena ha sido, más bien, una de las principales características no solo de la práctica científica jesuita en tiempos coloniales sino del estudio de ella en tiempos contemporáneos también. Andrés Prieto indicó que en América del Sur, una de las maneras más importantes de "fomentar la evangelización" de los nativos fue "la acomodación a las culturas indígenas". Los jesuitas tuvieron que aprender "la lengua y cultura de los indios, y usar dicha información para promover sus propios objetivos proselitistas" (Prieto, 2011: 6). Los misioneros de la Compañía, sin embargo, tendieron a marginalizar la "agencia nativa", es decir, borraron el rol que los nativos jugaron como transmisores o proveedores de la información que los jesuitas recogieron sobre la flora, fauna, demografía y geografía de Sudamérica (Prieto, 2011: 82). Por ello mismo, en estas páginas, mi intención ha sido examinar los indicios que nos permiten sostener, más bien, que, a pesar de la falta de fuentes como las que sostienen el caso jesuita en China, los nativos sudamericanos sí participaron, cumpliendo diversos papeles y funciones, en la acumulación y producción de conocimiento cartográfico y geográfico jesuita, con particular énfasis en su desenvolvimiento en el Amazonas español colonial.

De esta manera, por un lado, mi objetivo ha sido demostrar que la naturaleza colaborativa de la cartografía jesuita, usualmente asociada a la producida por los miembros de la Compañía enviados a Asia, también puede ser encontrada y analizada en el caso de los jesuitas enviados a América. Tanto los misioneros que fueron enviados a China como al Amazonas vinieron necesariamente a depender del conocimiento provisto 
por las sociedades locales. La única diferencia es que la disponibilidad de fuentes, generalmente escritas, ha creado la falsa impresión de que esto solamente pudo haber ocurrido entre la élite letrada nativa y los misioneros europeos en China. Sin embargo, investigaciones más recientes han empezado a desentrañar la naturaleza colaborativa de la ciencia jesuita en América también. Este artículo pretende entonces contribuir a dicha apertura historiográfica, subrayando cómo los nativos "iletrados" del Amazonas contribuyeron efectivamente al conocimiento espacial que los jesuitas obtuvieron del Nuevo Mundo. Si futuros estudios escudriñan más profundamente el caso americano, eso nos llevaría a la conclusión de que las prácticas científicas de los jesuitas en Asia y en América fueron mucho más parecidas de lo que previamente se pensaba y, en consecuencia, se podría hablar, al menos en el campo de la cartografía y geografía, de la existencia, en cuestión de objetivos y condiciones, de una auténtica ciencia global jesuita en tiempos modernos.

\section{Referencias Bibliográficas}

\section{Fuentes Secundarias}

\section{a) Artículos}

Almeida, A. (2003a). "Samuel Fritz and the Mapping of the Amazon", en Imago Mundi, No. 55, pp. 113-119.

Almeida, A. (2003b). "Samuel Fritz Revisited: The Maps of the Amazon and their Circulation in Europe". En Ramada Curto, D., A. Cattaneo y A. Almeida (eds.), La Cartografia Europea tra Primo Rinascimento e fine dell'llluminismo. Florence: Leo S. Olschki, pp. 133-153.

Barcelos, A. (2010). "A cartografia indígena no Rio da Prata colonial", en $O$ Brasil no Sul: cruzando fronteiras entre o regional e o nacional. X Encontro Estadual de História, ANPUH-RS. Santa Maria: UFSM, UNIFRA (http://www. eeh2010.anpuh-rs.org.br/resources /anais/9/1279585458 ARQUIVO trabalhoArturBarcelos.pdf)

Buisseret, D. (1997). "Jesuit Cartography in Central and South America", en Gagliano, J. y C. E. Ronan (eds.), Jesuit Encounters in the New World: Jesuit Chroniclers, Geographers, Educators and Missionaries in the Americas, 15491767. Rome: Institutum Historicum S.I., pp. 113-162.

Buisseret, D. (2007). "Spanish Colonial Cartography, 1450-1700", en Woodward, D. (ed.), The History of Cartography, Vol. 3, Libro 1. Chicago: Chicago University Press, pp. 1143-1171. 
Cormack, L. B. (2007). "Maps as Educational Tools in the Renaissance". En Woodward, D. (ed.), The History of Cartography, Vol. 3, Libro 1. Chicago, Chicago University Press, pp. 622-636.

Dias, C. (2012). "Jesuit Maps and Political Discourse: The Amazon River of Father Samuel Fritz", en The Americas, Vol. 69, No. 1, pp. 95-116.

Foss, T. (1988). "A Western Interpretation of China: Jesuit Cartography", en Ronan, C. E. y B. Oh (eds.), East Meets West: The Jesuits in China, 1582-1773. Chicago: Loyola University Press, pp. 209-251.

Godlewska, A. (1997). "Commentary: The Fascination of Jesuit Cartography", en Gagliano, J. y C. E. Ronan (eds.), Jesuit Encounters in the New World: Jesuit Chroniclers, Geographers, Educators and Missionaries in the Americas, 15491767. Roma: Institutum Historicum S.I., pp. 99-111.

Hostetler, L. (2009). "Contending Cartographic Claims? The Qing Empire in Manchu, Chinese, and European Maps", en Akerman, J. (ed.), The Imperial Map: Cartography and the Mastery of Empire. Chicago, The University of Chicago Press, pp. 93-132.

Jami, C. (1999). "'European Science in China' or 'Western Learning'? Representations of Cross-Cultural Transmission, 1600-1800", en Science in Context, Vol. 12, No. 3, pp. 413-434.

Kok, G. (2009). "Vestígios indígenas na cartografia do sertão da América portuguesa" en Anais do Museu Paulista, Vol. 17, No. 2, pp. 91-109.

Langer, P. (2009). "Cartas geográficas edificantes: $O$ imaginário da conversão dos povos indígenas nos mapas dos jesuítas Heinrich Scherer e Samuel Fritz", en P. Suess et al. (eds.), Conversão dos cativos: Povos indígenas e missão jesuítica, São Bernardo do Campo: Nhanduti, pp. 79-90.

Levinton, N. (2010). "La micro-región: espacio y tiempo en la cartografía producida por la interacción jesuítico-guaraní", en Anuario de Estudios Americanos, Vol. 67, No. 2, pp. 577-604.

Needham, J. (1996). "Chinese Astronomy and the Jesuit Mission: An Encounter of Cultures", en Storey, W. (ed.), Scientific Aspects of European Expansion. Aldershot: Variorum, pp. 283-304.

Qi, H. (2001). "Sino-French Scientific Relations through the French Jesuits and the Académie Royale des Sciences in the Seventeenth and Eighteenth Centuries", en Uhaley, S. y X. Wu (eds.), China and Christianity: Burdened Past, Hopeful Future. Armonk, NY: M. E. Sharpe, pp.137-147.

Reed, M. (2007). "A Perfume Is Best from Afar: Publishing China for Europe", en Reed, M. y P. Demattè (eds.), China on Paper: European and Chinese Works 
from the Late Sixteenth to the Early Nineteenth Century. Los Angeles, CA: The Getty Research Institute, pp. 9-27.

Song, G. y P. Demattè. (2007). "Mapping an Acentric World: Ferdinand Verbiest's Kunyu Quantu", en M. Reed y P. Demattè (eds.), China on Paper: European and Chinese Works from the Late Sixteenth to the Early Nineteenth Century. Los Angeles, CA: The Getty Research Institute, pp. 71-87.

Whitehead, N. (1998). "Indigenous Cartography in Lowland South America and the Caribbean", en Woodward, D. y G. M. Lewis (eds.), The History of Cartography, Vol. 2, Libro 3. Chicago: University of Chicago Press, pp. 301-326.

Witek, J. D. (1988). "Understanding the Chinese: A Comparison of Matteo Ricci and the French Jesuit Mathematicians Sent by Louis XIV", en C. E. Ronan y B. Oh (eds.), East Meets West: The Jesuits in China, 1582-1773. Chicago: Loyola University Press, pp. 62-102.

Yee, C. (1994). "Traditional Chinese Cartography and the Myth of Westernization", en Harley, J. B. y D. Woodward (eds.), The History of Cartography, Vol. 2, Libro 2,. Chicago: University of Chicago Press, pp. 170-202.

\section{b) Libros}

Barcelos, A. (2013). O Mergulho no Seculum: esploração, conquista e organização espacial jesuítica na América espanhola colonial. Porto Alegre: Animal.

Burrus, E. (1965). Kino and the Cartography of Northwestern New Spain. Tuczon, AZ: Arizona Pioneers' Historical Society.

Burrus, E. (1967). La obra cartográfica de la Provincia Mexicana de la Compañía de Jesús (1567-1967), Vol. 1. Madrid: José Porrúa Turanzas.

Elman, B. A. (2005). On Their Own Terms: Science in China, 1550-1900. Cambridge, Harvard University Press.

Fritz, S. (1922). Journal of the Travels and Labours of Father Samuel Fritz in the River of the Amazons between 1686 and 1723. Londres: Hakluyt Society.

Furlong, G. (1936). Cartografía jesuítica del Río de la Plata, Vol. 1. Buenos Aires: Talleres S.A. Casa Jacobo Peuser Ltda.

Latorre, O. (1988). Los mapas del Amazonas y el desarrollo de la cartografía ecuatoriana en el siglo XVIII. Guayaquil: Museos del Banco Central del Ecuador.

Prieto, A. (2011). Missionary Scientists: Jesuit Science in Spanish South America, 1570-1810. Nashville: Vanderbilt University Press.

Short, J. R. (2009). Cartographic Encounters: Indigenous Peoples and the Exploration of the New World. London: Reaktion Books. 
Sierra, V. (1944). Los jesuitas germanos en la conquista espiritual de HispanoAmérica. Siglos XVII-XVIII. Buenos Aires: Facultades de Filosofía y Teología, Institución Cultural Argentino-Germana.

c) Tesis

Lucero, I. (2004). La cartografía de la antigua provincia de Quito de la Compañía de Jesús. Tesis para optar al grado de Licenciado en Teología Sagrada. Boston: Weston Jesuit School of Theology, Boston College. 